\section{Vietnam Journal of Agricultural Sciences}

\title{
Growth and Physiological Responses of Sugarcane to Drought Stress at an Early Growth Stage
}

\author{
Bui The Khuynh, Vu Ngoc Thang, Vu Dinh Chinh \& \\ Pham Thi Thom
}

Faculty of Agronomy, Vietnam National University of Agriculture, Hanoi 131000, Vietnam

\begin{abstract}
A pot experiment was conducted in a net house to evaluate the effects of drought stress (a 20-day water withholding treatment from 100120 days after planting) on the growth and physiology of five sugarcane cultivars. The results showed that water stress at an early stage significantly affected sugarcane growth and physiology. Water stress resulted in reductions in plant height, stalk diameter, and leaf number of sugarcane, in addition to reductions in the photosynthetic pigment content, $F v / F m$, and SPAD (Soil Plant Analysis Development) readings after the 20-day withholding water period (120 DAP), and in stem, root, and leaf fresh weights, and leaf area at 150 DAP. Besides, drought stress led to increases in stomata density and decreases in stomata length. Variation was also found among the cultivars in response to water stress. Significant genotypic differences in stem fresh weight and leaf area under water stress among the cultivars were observed. The highest value of stem fresh weight under stressed conditions was recorded in ROC22 (50.6g), followed by QĐ159 (46.5g), ROC16 (46.2g), ROC10 (46.1g), and VL06 (44.4g). However, the highest DTI was recorded in ROC16, followed by VL06, ROC10, QĐ93159 , and ROC22, respectively.
\end{abstract}

\section{Keywords}

Sugarcane, drought stress, growth, physiological response

\section{Introduction}

Received: June 9, 2019

Correspondence to

btkhuynh@vnua.edu.vn

\section{ORCID}

Khuynh T. Bui

https://orcid.org/0000-0001-5554$752 X$

Drought is considered a major abiotic stress that limits crop production, resulting in severe reductions of their growth rate and development (Begcy et al., 2012). Sugarcane (Saccharum spp.) is an important crop used in the production of approximately $60 \%$ of the global sugar supply as well as in the production of ethanol and bioenergy (Amalraj et al., 2010). As a C4 plant with a high photosynthetic capacity, sugarcane is highly dependent on water 
availability. Sugarcane is mostly cultivated in tropical and sub-tropical rain-fed regions on both sides of the equator (from $35^{\circ}$ North to $35^{\circ}$ South) (Silva et al., 2013). In many of these regions, rainfall does not provide the amount of water required for the growth and photosynthetic activities of the crop, and thus water shortages remain a major limiting factor for achieving high yields of sugarcane. Even in humid tropical areas, inequality in rainfall distribution leads to reductions in growth or yield loss (Silva et al., 2013). A yield loss up to $60 \%$ due to drought has been recorded in sugarcane (Robertson et al., 1999). In Vietnam, the largest growing region of sugarcane is located along the central coast where drought is a recurring problem. Apart from irrigation practices, drought tolerance improvement is required to alleviate drought and water deficit problems, and to reduce yield losses. Successful selection and breeding for cultivars with drought tolerance can only be achieved when the mechanisms underlying drought tolerance in sugarcane are fully understood. Better understanding of the physiological mechanisms employed by the plant to better cope with drought and water deficits will enhance the success rate in selecting and breeding sugarcane for drought tolerance (Silva et al., 2013). Thus, the objectives of this study were to evaluate the effects of a water deficit on the growth of five sugarcane cultivars and analyze the genotypic differences in their levels of drought tolerance.

\section{Materials and Methods}

\section{Plant culture and water deficit treatment}

Five sugarcane cultivars (Table 1) were used in this study. A pot experiment was conducted in greenhouse conditions at the Faculty of Agronomy, Vietnam National
University of Agriculture. The mature stalks (8 months old) of five cultivars were selected, cut into short pieces of which each had one active bud, and used for propagating in germination trays containing moist sand. The uniformly germinated seedlings (buds $5-7 \mathrm{~cm}$ in height) were then transplanted into plastic containers with the dimensions of $25 \mathrm{~cm}$ in diameter and $35 \mathrm{~cm}$ in height, and filled with $15 \mathrm{~kg}$ of dry soil.

A two factorial experiment was laid out with five replications following a completely randomized design (CRD). The two water regimes (field capacity as the control and drought stress followed by recovery) were designated factor $\mathrm{A}$, while the five sugarcane cultivars were designated factor B. Water was supplied to all the treatments at the field capacity level from the time of seed cane planting to 100 days after planting (100 DAP). For the drought stress treatment, water was withheld for 20 days from 100 to 120 DAP. Re-watering then was done in the drought stress treatment to bring the soil back to the level of field capacity and maintained in that condition from 120 to 150 DAP. Soil moisture was regularly measured at a depth of 20 cm using a soil tester Takemura DM15 (Japan) every five days during the drought stress period. Mean values of the recorded soil moistures in the stressed treatment ranged from $78-85 \%, 75-82 \%$, $62-68 \%$, and $46-54 \%$ on the $5^{\text {th }}, 10^{\text {th }}, 15^{\text {th }}$, and $20^{\text {th }}$ days of withholding water, respectively.

\section{Measurements}

Plant height, stalk diameter, and leaf number were measured at 100,120 (end of the drought stress treatment), and 150 DAP (30 days after rewatering). The number of fully expanded leaves was counted, and the center point of the stalk was measured for stalk diameter using a vernier caliper.

Table 1. Origin of the five sugarcane cultivars used in the study

\begin{tabular}{|c|c|}
\hline Cultivar & Origin \\
\hline QĐ93-159 (Yuetang 93-159) & GSIRI, China \\
\hline $\mathrm{ROC} 10$ & TSRI, Taiwan \\
\hline ROC16 & TSRI, Taiwan \\
\hline ROC22 & TSRI, Taiwan \\
\hline Vien Lam 6 (VL6) & TSRI, Taiwan \\
\hline
\end{tabular}


Stomatal density and size were measured according to the methods of Camargo \& Marenco (2011). The youngest fully expanded leaves (5 leaves and 4 samples per leaf) were selected, and the midrib vein was removed. Stomatal density and stomatal size were determined from nail polish imprints taken from both the adaxial and abaxial leaf surfaces. Stomata were counted by calculating the view field using a stage micrometer placed under the microscope (Nikon Ys100) with a 10x objective lens. Stomatal size was measured from a sample of 20 stomata per leaf at 100x magnification.

\section{Chlorophyll a fluorescence and photosynthetic pigments measurements}

The emission of chlorophyll $a$ fluorescence was evaluated at 12:00 pm, using a modulated fluorometer (Opti-Sciences, OS30p+, USA), as described by Medeiros et al. (2013). The initial fluorescence $(F O)$, the maximum fluorescence $(F m)$, and the maximum quantum efficiency of photosystem II $(F v / F m)$ were then recorded after 30 minutes of dark adaptation using leaf-clips on the first fully expanded leaf.

For the quantification of chlorophyll $a$, chlorophyll $b$, and the carotenoids, $0.1 \mathrm{~g}$ of fresh, fully expanded leaves was collected, ground, and soaked in $10 \mathrm{~mL}$ of $90 \%$ acetone for $48 \mathrm{~h}$. Absorbance readings at the wavelengths of 663, 647, and $470 \mathrm{~nm}$ were measured in a spectrophotometer and used for the calculation of the chlorophyll $a$, chlorophyll $b$, and carotenoid contents (Arnold, 1949), and expressed as $\mathrm{mg} \mathrm{g}^{-}$ 1 fresh weight (FW). Root fresh weight, stem fresh weight, leaf fresh weight, and leaf area were measured at 150 DAP. SPAD chlorophyll readings were measured at 100,110 , and 120 DAP using portable chlorophyll meters (SPAD502, Minolta, Japan). Drought tolerant index (DTI) was determined following the methods of Hoang et al. (2018) where DTI equaled the dry stem weight under stressed conditions divided by the dry weight under well-watered conditions.

\section{Data analysis}

Analysis of variance (ANOVA) tests on the measured traits was performed using CropStat (version 7.2) and Sigmaplot 12.5. Treatment means were compared using the least significant difference (LSD) test.

\section{Results and discussion}

\section{Plant height, stalk diameter, and leaf number}

Drought stress can reduce leaf size, decrease stem growth and root expansion, increase hair density on leaves and stems, and alter plant and water relations (Farooq et al., 2012). After 20 days of withholding water, significant reductions in plant height, stalk diameter, and leaf number were recorded in the five cultivars (Table 2). This is consistent with the findings of Silva et al. (2008) and Smith et al. (2005) who reported that cane elongation and stalk height were negatively and strongly affected by drought. At 150 DAP (30 days after re-watering), the plant height and stalk diameter of all the cultivars had not fully recovered as large reductions in stalk diameter and plant height were still observed in the stressed treatments among the five cultivars. Significant differences among the five sugarcane cultivars were recorded in plant height, stalk diameter, and leaf number in the stressed period (120 DAP) and after the recovery period (150 DAP). At 120 DAP, the highest plant height was observed in ROC16 $(140.5 \mathrm{~cm})$, followed by ROC22, QĐ93-159, ROC10, and VL06 with values of $126.0,112.8,98.7$, and $79.5 \mathrm{~cm}$, respectively. The reduction of stem height may have been caused by the low soil water potential which resulted in smaller leaf sizes and a smaller number of leaves per plant (Reddy et al., 2003). After the recovery period (150 DAP), stalk diameters ranged from $10.9 \mathrm{~mm}$ (in VL06) to $16.1 \mathrm{~mm}$ (in ROC10). Jangpromma et al. (2012) reported that drought stress did not lead to significant variations in stalk diameter among sugarcane cultivars after a 10-day water withholding period. These differences compared with the current study may indicate differences among the cultivars, experimental conditions, and duration of the stress treatment. A drought occurring for more than 10 days was seen to result in severe reductions in root development and yield (Jangpromma et al., 2012). 
Table 2. Plant height, stalk diameter, and leaf number of different sugarcane genotypes before (100 days after planting, DAP) and after (120 DAP) a 20 day-drought, and 30 days after re-watering (150 DAP)

\begin{tabular}{|c|c|c|c|c|c|c|c|c|c|c|}
\hline \multirow{2}{*}{\multicolumn{2}{|c|}{ Treatment }} & \multicolumn{3}{|c|}{ Plant height $\left(\mathrm{cm} \mathrm{plant}^{-1}\right)$} & \multicolumn{3}{|c|}{ Stalk diameter (mm) } & \multicolumn{3}{|c|}{ Leaf number (leaves plant ${ }^{-1}$ ) } \\
\hline & & \multirow{2}{*}{$\begin{array}{c}100 \text { DAP } \\
82.3\end{array}$} & \multirow{2}{*}{$\begin{array}{c}120 \text { DAP } \\
105.2\end{array}$} & \multirow{2}{*}{$\begin{array}{c}150 \text { DAP } \\
152.0\end{array}$} & \multirow{2}{*}{$\begin{array}{c}100 \text { DAP } \\
8.7\end{array}$} & \multirow{2}{*}{$\begin{array}{c}120 \text { DAP } \\
13.1\end{array}$} & \multirow{2}{*}{$\begin{array}{c}150 \text { DAP } \\
17.1\end{array}$} & \multirow{2}{*}{$\begin{array}{c}100 \text { DAP } \\
7.0\end{array}$} & \multirow{2}{*}{$\begin{array}{c}120 \text { DAP } \\
9.7\end{array}$} & \multirow{2}{*}{$\begin{array}{c}150 \text { DAP } \\
10.7\end{array}$} \\
\hline ROC10 & FC & & & & & & & & & \\
\hline & Stressed & 84.0 & 92.2 & 146.0 & 8.3 & 9.4 & 15.1 & 7.0 & 6.7 & 7.0 \\
\hline \multirow[t]{2}{*}{ ROC16 } & FC & 100.0 & 161.7 & 200.0 & 8.6 & 12.2 & 14.2 & 5.3 & 7.0 & 8.0 \\
\hline & Stressed & 96.6 & 119.3 & 160.0 & 8.9 & 8.7 & 12.4 & 5.6 & 5.7 & 4.7 \\
\hline \multirow[t]{2}{*}{ ROC22 } & $\mathrm{FC}$ & 103.7 & 139.0 & 175.3 & 8.2 & 12.2 & 17.9 & 6.6 & 9.0 & 8.7 \\
\hline & Stressed & 90.3 & 112.3 & 148.4 & 7.7 & 8.2 & 13.8 & 6.0 & 6.3 & 6.3 \\
\hline \multirow{2}{*}{$\begin{array}{l}\text { QĐ93- } \\
159\end{array}$} & FC & 89.5 & 117.5 & 158.3 & 8.5 & 12.4 & 17.3 & 5.3 & 7.0 & 9.3 \\
\hline & Stressed & 85.6 & 108.0 & 148.5 & 8.3 & 8.7 & 13.0 & 5.3 & 6.3 & 7.7 \\
\hline \multirow[t]{2}{*}{ VL06 } & $\mathrm{FC}$ & 53.6 & 92.4 & 141.5 & 6.0 & 8.1 & 11.6 & 6.3 & 8.6 & 6.0 \\
\hline & Stressed & 61.5 & 68.9 & 83.1 & 6.2 & 7.1 & 10.3 & 6.3 & 5.6 & 4.3 \\
\hline \multicolumn{2}{|c|}{$\operatorname{LSD}_{0.05 \mathrm{C}^{*} \mathrm{~W}}$} & 14.6 & 12.0 & 16.9 & 2.0 & 1.6 & 2.2 & 0.8 & 1.4 & 1.8 \\
\hline \multirow[t]{5}{*}{ Mean } & ROC10 & 83.2 & 98.7 & 149.4 & 8.4 & 11.2 & 16.1 & 7.0 & 8.2 & 8.8 \\
\hline & ROC16 & 98.7 & 140.5 & 180.1 & 8.7 & 10.4 & 13.3 & 5.5 & 6.3 & 6.3 \\
\hline & ROC22 & 97.0 & 126.0 & 161.8 & 7.9 & 10.2 & 15.9 & 6.3 & 7.7 & 7.5 \\
\hline & $\begin{array}{l}\text { QĐ93- } \\
159\end{array}$ & 87.6 & 112.8 & 153.4 & 8.4 & 10.6 & 15.2 & 5.3 & 6.7 & 8.5 \\
\hline & VL06 & 57.5 & 79.5 & 112.3 & 6.6 & 7.6 & 10.9 & 6.3 & 7.2 & 5.1 \\
\hline $\operatorname{LSD}_{0.05 \mathrm{C}}$ & & 10.3 & 8.5 & 11.9 & 1.4 & 1.2 & 1.5 & 0.5 & 1.0 & 1.3 \\
\hline \multirow[t]{2}{*}{ Mean } & $\mathrm{FC}$ & 86.0 & 123.3 & 165.5 & 8.0 & 11.6 & 15.6 & 6.1 & 8.3 & 8.5 \\
\hline & Stressed & 83.6 & 99.6 & 137.4 & 8.0 & 8.4 & 12.9 & 6.0 & 6.1 & 6.0 \\
\hline $\operatorname{LSD}_{0.05 \mathrm{w}}$ & & 6.5 & 5.4 & 7.5 & 0.9 & 0.7 & 1.0 & 0.3 & 0.6 & 0.8 \\
\hline $\mathrm{CV}_{\%}$ & & 10.1 & 6.3 & 6.5 & 14.8 & 9.6 & 8.9 & 7.9 & 11.1 & 14.7 \\
\hline
\end{tabular}

Note: C: cultivar; W: water treatment; FC: field capacity (control); Stressed: drought stress treatment.

\section{Stomatal density and size}

Leaf stomata play a central role in controlling the exchange of $\mathrm{CO}_{2}$ and water vapor $(\mathrm{Xu} \&$ Zhou, 2008), and thus, are a crucial part of the stress response of plants to water deficits. Under drought, reductions in the photosynthetic rate can be caused by both stomatal and non-stomatal activities, depending on the drought intensity and species (Chaves et al., 2003). Our results revealed that the stomatal density was higher on the abaxial surface than on the adaxial surface under both the stressed and control (FC) conditions (Figure 1). Drought stress led to significant increases in the stomatal density on the abaxial surface of the cultivars ROC10, ROC22, and QĐ93-159, and on the adaxial surface of the cultivars ROC10, ROC22, and VL06. In addition, the results showed a decrease in the mean values of stomatal length in the sugarcane cultivars under stressed conditions compared to the control. Similar results were observed by Meng et al. (1999) and Xu \& Zhou (2008) in which stomatal density was negatively correlated with stomatal length under different drought stress conditions. An increase in stomatal density and a decrease in stomatal size are regarded as important adaptations of plants to drought and water deficits (Xu \& Zhou, 2008). Although stomatal density was found to increase under drought stress, the number of stomata per leaf decreased as the leaf area was reduced (Xu \& Zhou, 2008). However, Yang et al. (2007) showed that stomatal density varies according to drought intensification. An increase in stomatal density was recorded under light and moderate drought, but a decrease was observed in severe drought. 
(A)
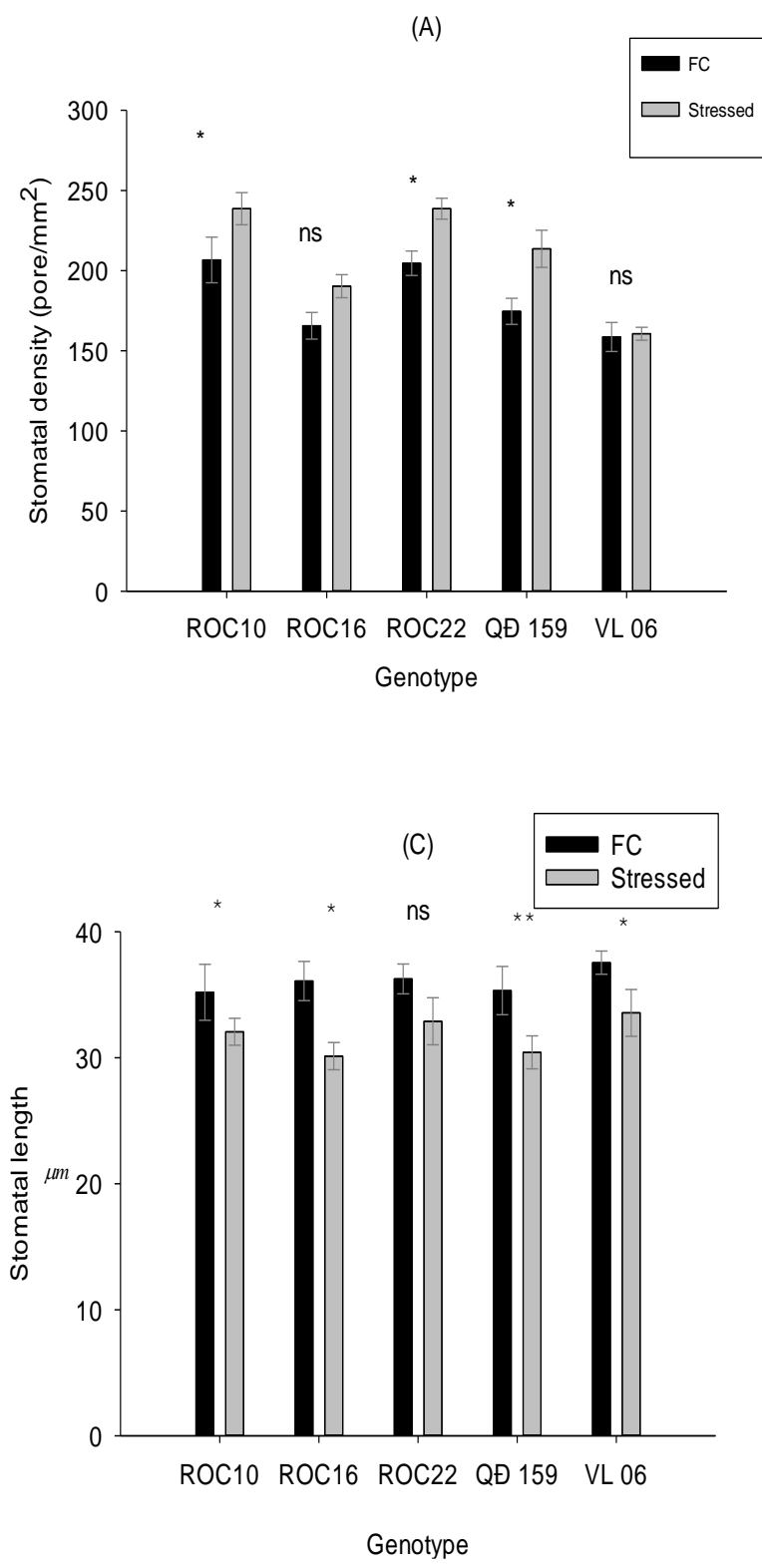

(B)

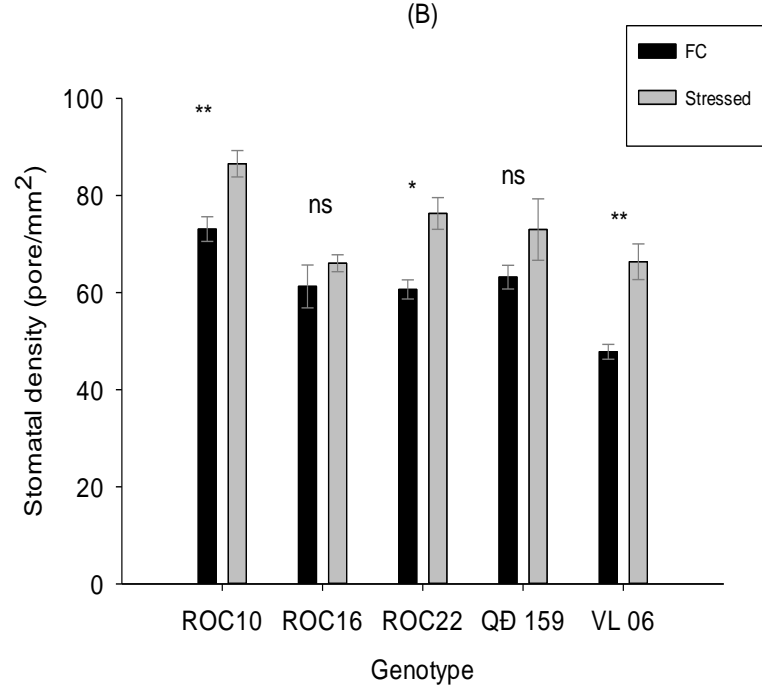

(D)

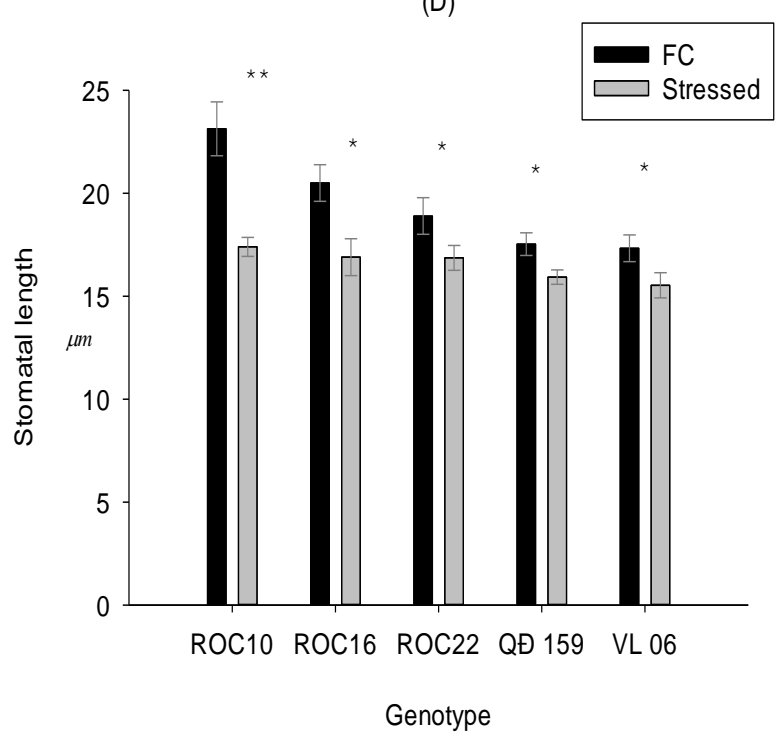

Note: $n s=$ not significant $;{ }^{*}=$ significant at $p=0.05 ;{ }^{* *}=$ significant at $p=0.01$.

Figure 1. Mean values of stomatal density on the abaxial (A) and adaxial (B) surfaces, and mean values of stomatal length on the abaxial (C) and adaxial (D) surfaces among cultivars

\section{Photosynthetic pigments}

Droughts have negative impacts on photosynthetic pigments. Depending on the drought intensity and duration, drought can cause damage to pigments or even deterioration of thylakoid membranes (Ashraf \& Harris, 2013). In this study, the results showed a decrease in both chlorophyll $a$ and $b$ content as consequences of drought stress in all the cultivars (Table 3 ). While a decrease of $36 \%$ was found in the chlorophyll $a$ content, drought stress also reduced the chlorophyll $b$ content by $61 \%$ compared to the control (FC), leading to changes in the chlorophyll $a / b$ ratio. However, no significant differences in carotenoid content were observed regardless of the cultivar or water treatment. Similar results have also been observed by Ashraf \& Harris (2013) and Mafakheri et al. (2010), who reported that reductions in the chlorophyll content from drought stress are due to 
Growth and Physiological Responses of Sugarcane to Drought Stress at an Early Growth Stage

Table 3. Effects of drought stress at an early stage on photosynthetic pigments at 120 DAP

\begin{tabular}{|c|c|c|c|c|c|c|}
\hline \multicolumn{2}{|c|}{ Treatment } & \multirow{2}{*}{$\frac{\text { Chla }\left(\mathrm{mg} \mathrm{g}^{-1}\right)}{0.946}$} & \multirow{2}{*}{$\begin{array}{c}\text { Chlb }\left(\mathrm{mg} \mathrm{g}^{-1}\right) \\
0.338\end{array}$} & \multirow{2}{*}{$\frac{\text { Carotenoid }\left(\mathrm{mg} \mathrm{g}^{-1}\right)}{0.208}$} & \multirow{2}{*}{$\begin{array}{c}\text { Chla/Chlb } \\
2.799\end{array}$} & \multirow{2}{*}{$\frac{\text { Total chl }}{1.284}$} \\
\hline ROC10 & $\mathrm{FC}$ & & & & & \\
\hline & Stressed & 0.729 & 0.258 & 0.203 & 2.826 & 0.987 \\
\hline \multirow[t]{2}{*}{ ROC16 } & $\mathrm{FC}$ & 0.955 & 0.343 & 0.207 & 2.784 & 1.298 \\
\hline & Stressed & 0.651 & 0.213 & 0.203 & 3.056 & 0.864 \\
\hline \multirow[t]{2}{*}{ ROC22 } & $\mathrm{FC}$ & 0.890 & 0.351 & 0.206 & 2.536 & 1.241 \\
\hline & Stressed & 0.763 & 0.235 & 0.208 & 3.247 & 0.998 \\
\hline \multirow[t]{2}{*}{ QĐ93-159 } & FC & 0.936 & 0.339 & 0.207 & 2.761 & 1.275 \\
\hline & Stressed & 0.704 & 0.209 & 0.198 & 3.368 & 0.913 \\
\hline \multirow[t]{2}{*}{ VL06 } & $\mathrm{FC}$ & 0.954 & 0.343 & 0.202 & 2.781) & 1.297 \\
\hline & Stressed & 0.579 & 0.220 & 0.197 & 2.632 & 0.799 \\
\hline $\operatorname{LSD}_{0.05 \mathrm{C}^{*} \mathrm{~W}}$ & & 0.163 & 0.043 & 0.009 & - & - \\
\hline \multirow[t]{5}{*}{ Mean } & ROC10 & 0.838 & 0.298 & 0.206 & - & - \\
\hline & ROC16 & 0.803 & 0.278 & 0.205 & - & - \\
\hline & ROC22 & 0.827 & 0.293 & 0.207 & - & - \\
\hline & QĐ93-159 & 0.820 & 0.274 & 0.203 & - & - \\
\hline & VL06 & 0.767 & 0.282 & 0.202 & - & - \\
\hline $\operatorname{LSD}_{0.05 \mathrm{C}}$ & & 0.011 & 0.0285 & 0.006 & - & - \\
\hline \multirow[t]{2}{*}{ Mean } & $\mathrm{FC}$ & 0.936 & 0.343 & 0.206 & - & - \\
\hline & Stressed & 0.685 & 0.227 & 0.202 & - & - \\
\hline LSD $_{0.05 W}$ & & 0.072 & 0.018 & 0.041 & - & - \\
\hline $\mathrm{CV}_{\%}$ & & 0.1 & 8.3 & 2.6 & - & - \\
\hline
\end{tabular}

Note: C: cultivar; W: water treatment; FC: field capacity (control); Stressed: drought stress treatment.

damage of the photosynthetic pigments and deterioration of the thylakoid membranes. The reduction of the chlorophyll content is mainly due to the destruction of pigments caused by oxidative damage when the plant is exposed to severe drought stress. Generally, drought stress leads to a greater reduction of the chlorophyll $b$ content than that of chlorophyll $a$ and thus, results in an increased ratio of chlorophyll $a / b$ (Ashraf \& Harris, 2013). Under adverse conditions such as drought, plants employ different physiological and metabolic strategies for survival. For instance, plants can synthesize antioxidants such as ascorbate, glutathione, and flavonoids (Medeiros et al., 2013), together with increasing the activity of antioxidant enzymes including peroxidase, superoxide dismutase, and catalases.

\section{SPAD readings and maximum photochemical efficiency (Fv/Fm)}

The maximum photochemical efficiency $(F v / F m)$ is positively correlated with the photosynthesis rate of a plant and thus, is used as an important parameter for quantifying a plant's response to drought stress (Silva et al., 2013). Maintaining a similar $F v / F m$ ratio between plants under drought stress and plants under wellirrigated conditions indicates a high efficiency of carbon assimilation and hence, the plant is better able to adapt to the stressed conditions (Silva et al., 2007). No significant differences in the $F v / F m$ ratios were found among all the cultivars at 100 and 110 DAP. All the cultivars had a $\mathrm{Fv} / \mathrm{Fm}$ ratio of 0.74 to 0.78 . However, at 120 DAP (20 days of withholding water), significant differences in the $F v / F m$ ratios were observed 
Table 4. SPAD meter readings and $F v / F m$ ratios of different sugarcane cultivars before (100 days after planting, DAP), after 10 days (110 DAP), and after 20 days of drought (120 DAP)

\begin{tabular}{|c|c|c|c|c|c|c|c|c|}
\hline \multirow{2}{*}{\multicolumn{2}{|c|}{ Treatment }} & \multicolumn{3}{|c|}{$\mathrm{Fv} / \mathrm{Fm}$} & \multicolumn{4}{|c|}{ SPAD readings } \\
\hline & & \multirow{2}{*}{$\begin{array}{c}100 \text { DAP } \\
0.765\end{array}$} & \multirow{2}{*}{$\begin{array}{c}110 \text { DAP } \\
0.776\end{array}$} & \multirow{2}{*}{$\frac{120 \mathrm{DAP}}{0.742}$} & \multirow{2}{*}{$\begin{array}{c}100 \text { DAP } \\
53.6\end{array}$} & \multirow{2}{*}{$\begin{array}{c}110 \text { DAP } \\
43.3\end{array}$} & \multirow{2}{*}{$\begin{array}{c}120 \mathrm{DAP} \\
45.5\end{array}$} & \multirow{2}{*}{$\begin{array}{c}150 \text { DAP } \\
39.0\end{array}$} \\
\hline $\mathrm{ROC} 10$ & $\mathrm{FC}$ & & & & & & & \\
\hline & Stressed & 0.767 & 0.764 & 0.633 & 51.0 & 44.2 & 36.9 & 44.4 \\
\hline \multirow[t]{2}{*}{$\mathrm{ROC16}$} & $\mathrm{FC}$ & 0.791 & 0.786 & 0.773 & 52.2 & 46.0 & 44.2 & 42.8 \\
\hline & Stressed & 0.781 & 0.741 & 0.679 & 52.7 & 45.2 & 40.1 & 44.3 \\
\hline \multirow[t]{2}{*}{ ROC22 } & $\mathrm{FC}$ & 0.788 & 0.784 & 0.738 & 50.7 & 45.7 & 45.7 & 42.6 \\
\hline & Stressed & 0.786 & 0.704 & 0.581 & 53.5 & 46.1 & 40.9 & 44.9 \\
\hline \multirow{2}{*}{$\begin{array}{l}\text { QĐ93- } \\
159\end{array}$} & $\mathrm{FC}$ & 0.780 & 0.771 & 0.755 & 48.3 & 46.8 & 43.7 & 41.7 \\
\hline & Stressed & 0.775 & 0.756 & 0.550 & 53.6 & 46.1 & 34.0 & 43.1 \\
\hline \multirow[t]{2}{*}{ VL06 } & $\mathrm{FC}$ & 0.764 & 0.780 & 0.752 & 47.7 & 44.2 & 43.9 & 39.1 \\
\hline & Stressed & 0.783 & 0.701 & 0.610 & 52.2 & 45.3 & 36.4 & 42.6 \\
\hline $\operatorname{LSD}_{0.05 \mathrm{C}^{*} \mathrm{~W}}$ & & 0.211 & 0.161 & 0.427 & 4.5 & 1.9 & 2.9 & 2.1 \\
\hline \multirow[t]{5}{*}{ Mean } & $\mathrm{ROC} 10$ & 0.766 & 0.770 & 0.687 & 52.3 & 43.8 & 41.2 & 41.7 \\
\hline & $\mathrm{ROC16}$ & 0.786 & 0.763 & 0.726 & 52.4 & 45.6 & 42.2 & 43.5 \\
\hline & ROC22 & 0.787 & 0.744 & 0.659 & 52.1 & 45.9 & 43.3 & 43.8 \\
\hline & QĐ93-159 & 0.778 & 0.763 & 0.653 & 51.0 & 46.4 & 38.9 & 42.4 \\
\hline & VL06 & 0.773 & 0.762 & 0.681 & 49.9 & 44.8 & 40.2 & 40.9 \\
\hline $\mathrm{LSD}_{0.05 \mathrm{C}}$ & & 0.149 & 0.114 & 0.303 & 3.2 & 1.4 & 2.1 & 1.4 \\
\hline \multirow[t]{2}{*}{ Mean } & $\mathrm{FC}$ & 0.778 & 0.779 & 0.752 & 50.5 & 45.2 & 44.6 & 41.2 \\
\hline & Stressed & 0.778 & 0.742 & 0.610 & 52.6 & 45.3 & 37.7 & 43.9 \\
\hline $\operatorname{LSD}_{0.05 \mathrm{~W}}$ & & 0.145 & 0.132 & 0.191 & 2.2 & 0.9 & 1.3 & 2.0 \\
\hline $\mathrm{CV}_{\%}$ & & 1.6 & 1.2 & 3.7 & 5.1 & 2.5 & 4.2 & 2.7 \\
\hline
\end{tabular}

Note: C: cultivar; W: water treatment; FC: field capacity (control); Stressed: drought treatment.

among cultivars. The highest $F v / F m$ ratio value was found in ROC16 (0.726) while the rest of the cultivars had no significant differences. Drought stress only led to a significant reduction in the $F v / F m$ ratio in the stressed treatment compared with the control at 120 DAP (20 days of water withholding). A $F v / F m$ ratio value of less than 0.75 indicates the beginning of stress and, therefore, a reduction in the photosynthetic capacity of the plant (Maxwell \& Johnson, 2010). Low values of the $\mathrm{Fv} / \mathrm{Fm}$ ratio have also been reported by Graca et al. (2010) and Silva et al. (2007) in sugarcane under severe drought.

A SPAD chlorophyll meter reading (SCMR) is considered a rapid assessment of the chlorophyll content in many crops including sugarcane, corn, and papaya (Jangproma et al., 2010). Our results showed that drought significantly reduced the SCMRs of plants under stressed conditions at the end of the drought stress treatment (120 DAP), which was consistent with the findings of Silva et al. (2007). A drought imposed 90 DAP led to reductions in the SCMRs, and more severe reductions were recorded in susceptible genotypes. SCMRs, therefore, can be used for the identification of drought-tolerant genotypes (Silva et al., 2007). Significant differences in the SCMRs were observed among the five cultivars at the end of the drought stress treatment. The highest mean SCMR value was recorded in ROC22 (43.8), followed by ROC16 (42.2), and was lowest in QĐ93-159 (38.6). Under stressed conditions, the 
SCMRs were maintained at an average of 40 in ROC22 and ROC16, which were significantly higher compared to those in ROC10, VL06, and QĐ93-159. This suggests a higher capacity of the ROC22 and ROC16 plants to conserve their photosynthetic pigment content during drought stress. According to Silva et al. (2013), a SCMR below 40 in sugarcane indicates the start of chlorophyll deficiency, which affects the photosynthetic activities of the plants. Thus, the low SCMRs (below 40) recorded in ROC10, VL06, and QĐ93-159 indicate drought stress sensitivities. No significant difference in terms of the SCMRs was found between the control and stressed treatments at 30 days after re-watering (150 DAP).
Plant fresh weight, leaf area (LA), and drought tolerance index (DTI) at recovery (150 DAP)

Sugarcane plants exposed to prolonged drought have been reported to experience a reduction in growth (Jaiphong et al., 2016). Our results showed that root, leaf, and stem fresh weights, and leaf area were significantly reduced in plants under the drought treatment relative to the control (Table 5). Fresh root weight was reduced by $51.5 \%$ compared to the drought stress treatment at 150 DAP. This matches with the findings in early studies by Medeiros et al. (2013), Jaiphong et al. (2016), and Silva et al. (2013). Significant differences in root fresh weight, leaf fresh weight, stem fresh weight, and

Table 5. Effects of drought stress at an early stage on the plant fresh weight, leaf area, and drought tolerance index (DTI) of five cultivars at 150 DAP

\begin{tabular}{|c|c|c|c|c|c|c|}
\hline \multicolumn{2}{|c|}{ Treatment } & \multirow{2}{*}{$\begin{array}{c}\text { Root fresh weight } \\
\left.\text { (g plant }^{-1}\right)\end{array}$} & \multirow{2}{*}{$\begin{array}{c}\text { Leaf fresh weight } \\
\left(\mathrm{g} \mathrm{plant}^{-1}\right)\end{array}$} & \multirow{2}{*}{$\begin{array}{c}\text { Stem fresh weight } \\
\left.\text { (g plant }^{-1}\right)\end{array}$} & \multirow{2}{*}{$\begin{array}{c}\begin{array}{c}\text { Leaf area } \\
\left(\mathrm{cm}^{2}\right)\end{array} \\
18.2\end{array}$} & \multirow{2}{*}{$\begin{array}{c}\begin{array}{c}\text { Drought tolerance } \\
\text { index (DTI) }\end{array} \\
-\end{array}$} \\
\hline $\mathrm{ROC} 10$ & $\mathrm{FC}$ & & & & & \\
\hline & Stressed & 30.7 & 76.5 & 46.1 & 9.5 & 0.59 \\
\hline \multirow[t]{2}{*}{$\mathrm{ROC} 16$} & $\mathrm{FC}$ & 50 & 188.8 & 71.2 & 22.5 & - \\
\hline & Stressed & 31.3 & 78.8 & 46.2 & 10.5 & 0.69 \\
\hline \multirow[t]{2}{*}{ ROC22 } & $\mathrm{FC}$ & 93.1 & 176.5 & 96.7 & 23 & - \\
\hline & Stressed & 41.3 & 115.6 & 50.6 & 17.1 & 0.55 \\
\hline \multirow[t]{2}{*}{ QĐ93-159 } & FC & 58.1 & 164.6 & 80.5 & 14.9 & - \\
\hline & Stressed & 21.2 & 82.5 & 46.5 & 8.8 & 0.57 \\
\hline \multirow[t]{2}{*}{ VL06 } & $\mathrm{FC}$ & 46.5 & 91.3 & 64.7 & 17.2 & - \\
\hline & Stressed & 26.7 & 54.9 & 44.4 & 5.7 & 0.68 \\
\hline $\operatorname{LSD}_{0.05 \mathrm{C}^{*} \mathrm{w}}$ & & 4.1 & 10.5 & 4.4 & 1.9 & \\
\hline \multirow[t]{5}{*}{ Mean } & $\mathrm{ROC10}$ & 43.9 & 117.5 & 62.7 & 13.9 & \\
\hline & ROC16 & 40.6 & 133.8 & 58.7 & 16.5 & \\
\hline & ROC22 & 67.2 & 146.1 & 73.6 & 20.1 & \\
\hline & QĐ93-159 & 39.6 & 123.5 & 63.5 & 11.8 & \\
\hline & VL06 & 36.6 & 73.1 & 54.5 & 11.4 & \\
\hline $\operatorname{LSD}_{0.05 \mathrm{C}}$ & & 2.8 & 7.4 & 3.1 & 1.3 & \\
\hline \multirow[t]{2}{*}{ Mean } & $\mathrm{FC}$ & 60.9 & 155.9 & 78.5 & 19.2 & \\
\hline & Stressed & 30.2 & 81.6 & 46.8 & 10.3 & \\
\hline LSD $_{0.05 \mathrm{~W}}$ & & 1.8 & 4.7 & 2 & 0.9 & \\
\hline $\mathrm{CV}_{\%}$ & & 5.2 & 5.2 & 4.2 & 7.8 & \\
\hline
\end{tabular}

Note: C: cultivar; W: water treatment; FC: field capacity (control); Stressed: drought treatment. 
leaf area were found among sugarcane cultivars. The mean values of stem fresh weight ranged from 54.5g (in VL06) to $73.6 \mathrm{~g}$ (in ROC22). Significant differences in stem fresh weight and leaf area were also found among the cultivars under drought stress. The highest value of stem fresh weight under stressed conditions was recorded in ROC22 (50.6g), followed by QĐ93159 (46.5g), ROC16 (46.2g), ROC10 (46.1g), and VL06 (44.4g). Leaf area also varied among the sugarcane cultivars and ranged from $11.4 \mathrm{~cm}^{2}$ in VL06 to $20.1 \mathrm{~cm}^{2}$ in ROC22. A reduction in plant growth under water deficit conditions can be seen as the consequence of the decrease in cell elongation caused by the interruption of water flow from the xylem to surrounding elongation cells, the increase in cell sap concentration, and the dehydration of the protoplasm (Nonami, 1998; Larcher, 2003). Low biomass accumulation of sugarcane, when exposed to drought stress, can be explained by reductions in light interception, plant extension rate, and photosynthetic capacity (Koonjah et al., 2006). The drought tolerance index (DTI) has been used as an important parameter in evaluating the tolerance ability of crops. Among the sugarcane cultivars, the highest DTI was recorded in ROC16, followed by VL06, ROC10, QĐ93-159, and ROC22, respectively.

\section{Conclusions}

Drought stress at an early growth stage (100120 DAP) significantly affected the growth and physiological characteristics of five sugarcane cultivars. A 20-day water withholding treatment resulted in reductions in plant height, stalk diameter, and leaf number of sugarcane, in addition to reductions in photosynthetic pigment content, $F v / F m$, and SPAD readings at 120 DAP, and in stem, root, and leaf fresh weights, and leaf area at 150 DAP (30 days after re-watering). Furthermore, drought stress led to reductions in stomatal density and increases in stomatal length. Variation was also found among the cultivars in response to drought stress. The highest value of stem fresh weight under stressed conditions was recorded in ROC22 (50.6g), followed by QĐ93159 (46.5g), ROC16 (46.2g), ROC10 (46.1g), and VL06 (44.4g). However, the highest DTI was recorded in ROC16, followed by VL06, ROC10, QĐ93-159, and ROC22, respectively.

\section{Conflicts of Interest}

The authors declare no conflicts of interest.

\section{References}

Amalraj R. S., Selvaraj N., Veluswamy G. K., Rananujan R. P., Muthurajan R. \& Palaniyandi M. (2010). Sugarcane proteomics: Establishment of a protein extraction method for 2-DE in stalk tissues and initiation of sugarcane proteome reference map. Electrophoresis. 31: 1959-1974.

Arnon D. I. (1949). Copper enzymes in isolated chloroplasts, polyphenoxidase in Beta vulgaris. Plant Physiology. 24(1): 1-15.

Ashraf M. \& Harris P. J. C. (2013). Photosynthesis under stressful environments: An overview. Photosynthetica. 51(2): 163-190.

Begcy K., Mariano E. D., Gentile A., Lembke C. G., Zingaretti S. M., Souza G. M. \& Menossi M. (2012). A novel stress-induced sugarcane gene confers tolerance to drought, salt and oxidative stress in transgenic tobacco plants. PLoS One. 7:e44697.

Camargo M. A. B. \& Marenco R. A. (2011). Density, size and distribution of stomata in 35 rainforest tree species in Central Amazonia. Acta Amazonia. 41(2): 205-212.

Chaves M. M., Maroco J. P. \& Pereira J. S. (2003). Understanding plant responses to drought-from genes to the whole plant. Functional Plant Biology. 30: 239264.

Farooq M., Hussain M., Wahid A. \& Siddique K. H. M. (2012). Drought stress in plants: an overview. In: Aroca R. (Eds.) Plant responses to drought stress. Springer, Berlin/Heidelberg. 1-33.

Graça J. P., Rodrigues F. A., Farias J. R. B., Oliveira M. C. N., Hoffmann-Campo C. B. \& Zingaretti S. M. (2010). Physiological parameters in sugarcane cultivars submitted to water deficit. Brazilian Journal of Plant Physiology. 22: 189-197.

Hoang D. T., Hiroo T. \& Yoshinobu K. (2018). Nitrogen use efficiency and drought tolerant ability of various sugarcane varieties under drought stress at early growth stage. Plant Production Science. 22: 250-261.

Jaiphong T., Tominaga J., Watanabe K., Nakabaru M., Takaragawa H., Suwa R., Ueno M. \& Kawamitsu Y (2016). Effects of duration and combination of drought and flood conditions on leaf photosynthesis, growth and sugar content in sugarcane, Plant Production Science. 19: 427-437.

Jangpromma N., Thammasirirak S., Jailsil P. \& Songsri P. (2012). Effects of drought and recovery from drought 
stress on above ground and root growth, and water use efficiency in sugarcane (Saccharum officinarum L.). Australian Journal of Crop Science. 6: 1298-1304.

Jangpromma N., Songsri P. \& Jaisil P. (2010). Rapid assessment of chlorophyll content in sugarcane using a SPAD chlorophyll meter across different water stress conditions. Asian Journal of Plant Science. 9: 368-374.

Koonjah S. S., Walker S., Singels A., Van Antwerpen R. $\&$ Nayamuth A. R. (2006). A quantitative study of water stress effect on sugarcane photosynthesis. Proceedings of the South African Sugarcane Technologists' Association. 80: 148-158.

Larcher W. (2003). Physiological plant ecology: Ecophysiology and stress physiology of functional groups ( $4^{\text {th }}$ ed). Springer-Verlag. 401-416.

Mafakheri A., Siosemardeh A. \& Bahramnejad B. (2010). Effect of drought stress on yield, proline and chlorophyll contents in three chickpea cultivars. Australian Journal of Crop Science. 4: 580-585.

Maxwell K. \& Johnson G. N. (2000). Chlorophyll florescence: a practical guide. Journal of Experimental Botany. 51: 659-668.

Meng L., Li L., Chen W., Xu Z. \& Liu L. (1999). Effect of water stress on stomatal density, length, width and net photosynthetic rate in rice leaves. Journal of Shenyang Agricultural University. 30: 477-480.

Medeiros D. B., Silva E. C., Nogueira R. J. M. C., Teixeira M. M., Buckeridge M. S. (2013). Physiological limitations in two sugarcane varieties under water suppression and after recovering. Theoretical and Experimental Plant Physiology. 25: 213-222.

Nonami H. (1998). Plant water relations and control of cell elongation at low water potentials. Journal of Plant
Research. 111: 373-382.

Robertson M. J., Inman-Bamber N. G., Muchow R. C. \& Wood A. W. (1999). Physiology and productivity of sugarcane with early and mid-season water deficit. Field Crop Research. 64: 211-227.

Reddy T. Y., Reddy V. R. \& Anbumozhi V. (2003). Physiological response of groundnut (Arachis hypogea L.) to drought stress and its amelioration: A critical review. Plant Growth Regulation. 41: 75-88.

Silva M. A., Jifon J. L., Santos C. M., Jadoski C. J. \& Silva J. A. G. (2013). Photosyntheitc capacity and water use efficiency in sugarcane genotypes subject to water deficit during early growth phase. Brazilian Archives of Biology and Technology. 56: 735-748.

Silva M. A., Jifon J. L., Silva J. A. G. \& Sharma V. (2007). Use of physiological parameters as fast tools to screen for drought tolerance in sugarcane. Brazilian Journal of Plant Physiology. 19: 735-748.

Silva M. A., Silva J. A. G., Enciso J., Sharma V. \& Jifon J. (2008). Yield components as indicators of drought tolerance of sugarcane. Scientia Agricola. 65: 620-627.

Smith D. M., Inman-Bamber N. G. \& Thorburn P. J. (2005). Growth and function of the sugarcane root system. Field Crops Research. 92: 169-183.

Xu Z. \& Zhou Z. (2008). Responses of leaf stomatal density to water status and its relationship with photosynthesis in a grass. Journal of Experimental Botany. 59: $3317-$ 3325 .

Yang L., Han M., Zhou G. \& Li J. (2007). The changes of water-use efficiency and stoma density of Leymus chinensis along Northeast China Transect. Acta Ecologica Sinica. 27: 16-24. 